\title{
Impact of Different Bus Stop Designs on Bus Operating Time Components
}

\author{
Xiaodong Liu, Yao Yang, Meng Meng, Andreas Rau \\ TUM CREATE Ltd., Singapore
}

\begin{abstract}
The design of bus stops significantly affects bus operation. The delay time caused by inappropriate bus stop design adversely influences the efficiency of the system. This paper aims to examine the influence of bus stops on bus operating time components through statistical analysis, using Singapore as a case study. Two common types of bus stops, bus bay and curb-side stop, were investigated during the field survey to obtain actual data of bus operation at stops. Sixteen stops were chosen in pairs to compare the differences in operating time at bus stops. Bus operating times, including acceleration time, dwell time, deceleration time, and delay time, were recorded, with five types of delay time categorized. A total of 2,653 valid data records were collected and processed. The results showed that buses have better operational performance at curb-side stops than at bus bays in terms of average passenger boarding and alighting time and acceleration time. These findings have operational and planning implications for transport authorities and operators with regard to evaluating the performance of bus operation and improving the design of bus stops.
\end{abstract}

Keywords: Bus efficiency, bus travel time, dwell time, bus bay, curb-side stop

\section{Introduction}

Bus operation efficiency is important to urban traffic systems. It involves macroscopic planning, but operational aspects at the microscopic level are crucial as well. The reduction of bus travel times will improve the quality of service for the passengers and also reduce the operating cost for operators. Travel times can be reduced by mitigating time losses at intersections, introducing dedicated bus lanes, etc. Many studies have been conducted to investigate the operating time for entire bus operation (Shrestha and Zolnik 2013) or specific time components including running time (SurprenantLegault and El-Geneidy 2011), delay at intersection (Rakha and Zhang 2004) and arrival and dwelling at stops (Yu et al. 2011; Dueker et al. 2004; Tirachini 2013; Sun et al. 2014; Rajbhandari et al. 2003; Zhou et al. 2009). 
Bus stop design has a strong influence on the operating time components of buses. To improve the quality of public transport operation, it is important to understand the differences in bus stop designs in terms of operating time components at stops; this forms the research question of this paper. The investigation has important implications for public transport stakeholders, including transport authorities and operators, on operation and planning.

Currently, there are three common types of bus stops: bus bay, curb-side stop, and bus bulb (Fitzpatrick et al. 1996). As shown in Figure 1, bus bays have a dedicated busstopping area away from the road lanes used for traveling. These are the prevailing bus infrastructure in many megacities in Asia where bus transit is a major transport mode, including Beijing, Singapore, Hong Kong, and Tokyo. It is generally recommended that bus bays be provided at locations along roads with high traffic volume and arterial roadways with higher cruising speeds (Koshy and Arasan 2008). Curb-side stops and bus bulbs use a marked or signed portion of the through-traffic lanes for the boarding and alighting of passengers. Curb-side bus stops are widely used in many cities and municipalities, such as Auckland, Washington, London, British Columbia, and Tauranga city. A bus bulb (nub) is an extension of the sidewalk from the curb of a parking lane into the edge of the through lane on a road. Thus, bus bulbs have similar performance as curb-side stops.

FIGURE 1.

Selected street-side bus stop design
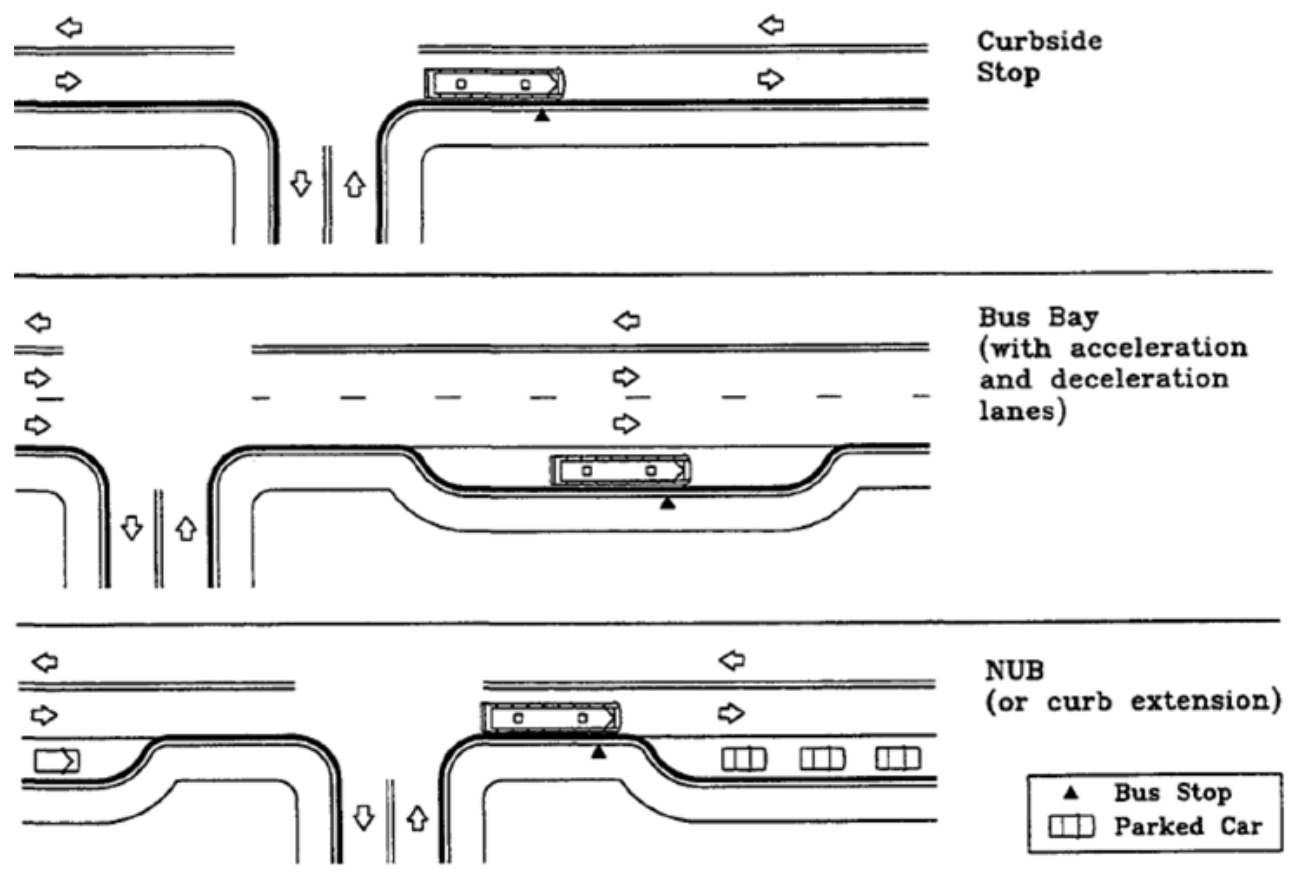

Source: Fitzpatrick et al. 1996

The bus operating time at a bus stop consists of deceleration time, dwell time, and acceleration time. Deceleration time is the time a bus spends to decelerate from cruising speed to a full stop when approaching a bus stop. Dwell time is the time when a bus dwells at a stop and includes the time needed for doors to open and close and 
the time for passengers to board and alight. Acceleration time is the time taken for a bus to leave a stop and merge back into the through lane. Buses may experience delays at all three stages, which leads to additional time needed for them to complete their journeys. Therefore, a fourth time component, delay time, is added in this study to fully understand bus operating time at bus stops. Five common types of delay time are considered in this study:

- Re-entry delay - This occurs when a bus leaves the stop but fails to immediately merge back into the through lane due to high traffic volume. It occurs only at bus bays because buses remain in the through lanes while dwelling at curb-side stops.

- Queuing delay - During peak hours, it is usual that multiple buses arrive at a stop at the same time. Due to the limited available berths, some buses may have to queue.

- Boarding and alighting delay - This type of delay is caused by passengers during the boarding and alighting process. For example, additional time is needed for passengers in wheelchairs to board or alight the bus.

- Delay caused by stopped or parked vehicles - When a bus leaves or approaches a stop, it may be obstructed by illegally-parked vehicles and may require additional maneuvers.

- Delay caused by vehicles queueing in front of a traffic signal - During peak hours, accumulated vehicle queues from downstream intersections may prevent a bus from leaving a stop, resulting in additional waiting time.

During operation at stops, buses may encounter more than one type of delay. Such situations are also considered in this study.

This paper investigates the differences in bus operating times at bus bays and curbside stops via a survey in Singapore. The bus system in Singapore accounts for $49 \%$ of the 3.75 million passenger trips made by public transport per day (Land Transport Authority 2015). By 2014, there were about 4,700 bus stops island-wide (Land Transport Authority 2015), with two common types: bus bays and curb-side stops. Bus bulbs are not used in Singapore, as discovered during the field observations, due to limited on-street parking.

\section{Literature Review}

Several surveys in different cities have been conducted to identify the operational differences at bus bays and curb-side stops. All had different survey designs and purposes and, therefore, cannot be compared easily. However, the experiences of other cities could help to develop a better understanding of the operational impact of different bus stop designs. A study in Beijing (Xu et al. 2010) investigated the differences in acceleration, deceleration, and dwell times at bus bays and curb-side stops under optimal operation conditions (no queuing, no re-entry delays, etc.). The results showed an average deceleration time of $9.0 \mathrm{~s}$ at bus bays and $8.5 \mathrm{~s}$ at curb-side stops. The average acceleration time ranged from $10.7 \mathrm{~s}$ at bus bays to $10.9 \mathrm{~s}$ at curb-side stops. Boarding 
and alighting times were not published. Another survey in Beijing in 2013 (Chen et al. 2013) analysed the situation by including all kinds of possible delays. The average deceleration time increased to $11.1 \mathrm{~s}$ at bus bays and $9.7 \mathrm{~s}$ at curb-side bus stops. The study showed an average acceleration time of 11.1s (including re-entry delays) at bus bays and $10.2 \mathrm{~s}$ at curb-side stops. The boarding and alighting times per passenger ranged from $2.3 \mathrm{~s}$ to $2.4 \mathrm{~s}$ at bus bays and from $1.8 \mathrm{~s}$ to $2.5 \mathrm{~s}$ at curb-side stops, both depending on the load factor of the bus.

A study in London (Transport for London 2006) analyzed the changes in bus operation by converting three bus bays into curb-side stops. As a result, the re-entry delays were reduced by $3 \%$ to $13 \%$. The absolute values of the changes in acceleration, deceleration, and re-entry delays were not published. The original boarding time at the bus bays ranged from $2.6 \mathrm{~s}$ to $3.8 \mathrm{~s}$ per passenger and improved by $0.5 \mathrm{~s}$ to $1 \mathrm{~s}$ per passenger after the conversion. A survey in Ottawa (Genivar 2011) showed that the deceleration time at bus bays ranges from $1 \mathrm{~s}$ to $2 \mathrm{~s}$ and the acceleration plus re-entry delay is $4 \mathrm{~s}$ to $5 \mathrm{~s}$ longer than at curb-side stops. This study could not identify any differences in the dwell time per passenger between the two bus stop designs. Wang et al (2016) proposed a method to estimate bus dwell time at a bus stop, where the average boarding and alighting time was explicitly calibrated considering different channel doors. The average deceleration and acceleration time were not estimated.

Table 1 provides a summary of the results from the different surveys. The results show that bus bays have longer deceleration and acceleration delays than curb-side bus stops. All studies except the one in Ottawa indicate longer boarding and alighting times per passenger at bus bays.

TABLE 1. Summary of Results from International Surveys

\begin{tabular}{|c|c|c|c|c|}
\hline Study & Bus Stop Design & $\begin{array}{c}\text { Average Deceleration } \\
\text { Time }\end{array}$ & $\begin{array}{c}\text { Average Acceleration } \\
\text { Time }\end{array}$ & Boarding/Alighting Time per Passenger \\
\hline \multirow{2}{*}{$\begin{array}{l}\text { Xu, Kwami, \& Yang, } \\
2010\end{array}$} & Bus bay & $9.0 \mathrm{~s}$ & $10.7 \mathrm{~s}$ & $\begin{array}{l}\text { 2.1s (single-channel door) } \\
1.7 \mathrm{~s} \text { (double-channel doors) }\end{array}$ \\
\hline & Curb-side stop & $8.5 \mathrm{~s}$ & $10.9 \mathrm{~s}$ & - \\
\hline \multirow{2}{*}{$\begin{array}{l}\text { Chen, Zhou, Zhou, } \\
\text { \& Mao, } 2013\end{array}$} & Bus bay & $11.11 \mathrm{~s}$ & $11.12 \mathrm{~s}$ & $\begin{array}{l}2.22 \mathrm{~s} \text { (load factor }<0.7 \\
2.37 \mathrm{~s} \text { (load factor }>=0.7)\end{array}$ \\
\hline & Curb-side stop & $9.74 \mathrm{~s}$ & $10.2 \mathrm{~s}$ & $\begin{array}{c}1.82 \mathrm{~s} \text { (load factor }<0.55) \\
2.49 \mathrm{~s} \text { (load factor }>=0.55)\end{array}$ \\
\hline \multirow{2}{*}{$\begin{array}{l}\text { Transport for } \\
\text { London, } 2006\end{array}$} & Bus bay & - & \multirow{2}{*}{$\begin{array}{l}3-13 \% \text { reduction by curb- } \\
\text { side stops, compared with } \\
\text { bus bays }\end{array}$} & $2.8-3.8 \mathrm{~s}$ \\
\hline & Curb-side stop & - & & $0.5-1 \mathrm{~s}$ faster than bus bay \\
\hline \multirow{2}{*}{ Genivar, 2011} & Bus bay & \multirow{2}{*}{$\begin{array}{l}1-2 \text { s longer at bus bays } \\
\text { compared to curb-side }\end{array}$} & \multirow{2}{*}{$\begin{array}{l}4-5 \mathrm{~s} \text { longer at bus bays } \\
\text { compared to curb-side }\end{array}$} & \multirow{2}{*}{$\begin{array}{l}\text { 3.5s, with no difference between curb-side } \\
\text { and bus bay }\end{array}$} \\
\hline & Curb-side stop & & & \\
\hline \multirow[b]{2}{*}{ Wang et al. (2016) } & Bus bay & - & - & \multirow{2}{*}{$\begin{array}{l}\text { Boarding time: } 2.5-4.0 \mathrm{~s} \text { (single-channel } \\
\text { door); } 0.6-2.5 \mathrm{~s} \text { (multiple- channel doors) } \\
\text { Alighting time: } 2.1-3.3 \mathrm{~s} \text { (single-channel } \\
\text { door); } 0.5-3.3 \mathrm{~s} \text { (multiple-channel doors) }\end{array}$} \\
\hline & Curb-side stop & - & - & \\
\hline
\end{tabular}




\section{Field Survey}

To analyze the operational differences between bus bays and curb-side stops in Singapore, eight locations were chosen. The survey was conducted at each location by comparing the bus bay and curb-side stop in a "bus stop survey pair" (BSSP), which consisted of two successive stops: a bus bay and a curb-side stop (Figure 2).

FIGURE 2.

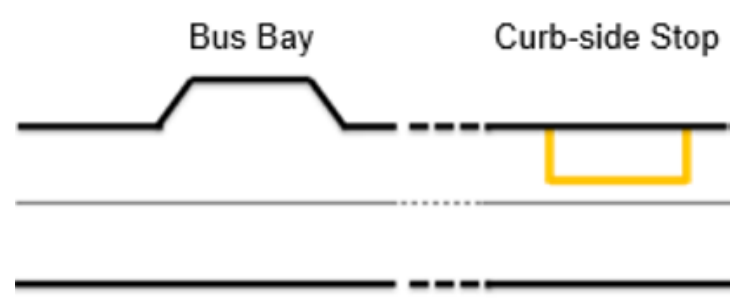

To minimize the influence of factors other than the stop design (e.g., traffic volume, driving characteristics of drivers, bus loading factor, etc.) as much as possible, the BSSPs were selected according to the following criteria:

- A BSSP consists of two successive stops: a bus bay and a curb-side stop.

- Both stops have one berth.

- No traffic signals directly near the stops.

- No heavy congestion at both stops.

- Similar numbers of bus service lines at both stops.

- Similar passenger demand, but no crowding, at both stops.

The locations of the BSSPs were chosen to ensure that all criteria listed above were satisfied and that the locations were evenly distributed over Singapore. Table 2 shows a summary of the selected stops. Most of the selected stops are connected to residential areas and are a certain distance from both upstream and downstream intersections.

The survey was carried out during morning peak hours (7:30-9:30 AM) and evening peak hours (5:30-7:30 PM) on weekdays from July 16-31, 2014. Each location was surveyed for two days to gather sufficient data, including:

- Basic bus information, including service number, type of bus (single-decker, double-decker, or articulated bus); bus delay type: re-entry delay, queuing delay, boarding and alighting delay, delay caused by stopped or parked vehicles, and delay by vehicles queuing in front of traffic signal

- Position of bus in the service queue, if berth occupied by other buses

- Bus operating times at stops, including deceleration time, dwell time, acceleration time

- Passenger volume - number of passengers boarding and alighting from each door of bus 
TABLE 2. Characteristics of Selected Bus Stop Survey Pairs

\begin{tabular}{|c|c|c|c|c|c|}
\hline BSSP & Stop Type & $\begin{array}{l}\text { Number of Through } \\
\text { Lanes per Direction }\end{array}$ & $\begin{array}{l}\text { Upstream Signalized } \\
\text { Intersection Distance* }\end{array}$ & $\begin{array}{l}\text { Downstream Signalized } \\
\text { Intersection Distance }\end{array}$ & Surrounding Areas \\
\hline \multirow{2}{*}{1} & Bus bay & 2 & $200 \mathrm{~m}$ & - & Residential area \\
\hline & Curb-side stop & 2 & $140 \mathrm{~m}$ & $110 \mathrm{~m}$ & Open area with pedestrian walk \\
\hline \multirow{2}{*}{2} & Bus bay & 2 & $210 \mathrm{~m}$ & $160 \mathrm{~m}$ & Residential area \\
\hline & Curb-side stop & 2 & $100 \mathrm{~m}$ & - & Residential area \\
\hline \multirow{2}{*}{3} & Bus bay & 2 & - & $110 \mathrm{~m}$ & Residential area \\
\hline & Curb-side stop & 2 & $260 \mathrm{~m}$ & - & Residential area \\
\hline \multirow{2}{*}{4} & Bus bay & 2 & - & $240 m$ & Residential area \\
\hline & Curb-side stop & 2 & $90 \mathrm{~m}$ & - & Residential area \\
\hline \multirow{2}{*}{5} & Bus bay & 2 & $230 \mathrm{~m}$ & $130 \mathrm{~m}$ & Residential area \\
\hline & Curb-side stop & 2 & $190 \mathrm{~m}$ & - & Residential area \\
\hline \multirow{2}{*}{6} & Bus bay & 2 & $180 \mathrm{~m}$ & $180 \mathrm{~m}$ & Park \\
\hline & Curb-side stop & 2 & $380 \mathrm{~m}$ & - & Open area \\
\hline \multirow{2}{*}{7} & Bus bay & 2 & - & $140 \mathrm{~m}$ & Residential area \\
\hline & Curb-side stop & 2 & $410 m$ & - & Residential area \\
\hline \multirow{2}{*}{8} & Bus bay & 2 & $160 \mathrm{~m}$ & $240 \mathrm{~m}$ & Residential area \\
\hline & Curb-side stop & 2 & $140 \mathrm{~m}$ & - & Residential area \\
\hline
\end{tabular}

"If there is another bus stop between a certain stop and its upstream/downstream intersection, distance marked as "-".

\section{Result and Analysis}

With incomplete data and skipped services filtered out, the data collection process led to 2,653 valid data records, comprising 1,256 valid data records at bus bays and 1,397 at curb-side stops. The analysis focuses on three parts: delay type, deceleration and acceleration times, and dwell time. The study on delay type includes basic statistics and their differences between delays at both bus bays and curb-side stops. With the assumption that the deceleration and acceleration times are different at bus bays and curb-side stops, hypothetical tests were applied for further data analysis. Finally, a regression model was applied to investigate the relationship between bus dwell time and the number of passengers boarding or alighting.

\section{Delay-type Analysis}

In total, 545 delayed records were collected at bus bays and 274 at curb-side bus stops. These delays were recorded according to the five categories mentioned above. The details of the distributions of the delay types are presented in Table 3. 
TABLE 3.

Distributions of Different

Delay Types at Bus Bays and

Curb-side Stops

\begin{tabular}{|l|r|r|r|r|}
\hline \multirow{2}{*}{ Delay Type } & \multicolumn{2}{c|}{ Bus Bay } & \multicolumn{2}{c|}{ Curb-side Stop } \\
\cline { 2 - 5 } & \multicolumn{1}{c}{ Total } & Frequency* & \multicolumn{1}{c|}{ Total } & Frequency* \\
\hline Total valid data records & 1,256 & $100 \%$ & 1,397 & $100 \%$ \\
\hline No Delay & 703 & $56 \%$ & 1,110 & $79 \%$ \\
\hline Delayed & 545 & $43 \%$ & 274 & $20 \%$ \\
\hline Re-entry delay & 271 & $22 \%$ & - & - \\
\hline Queuing delay & 118 & $9 \%$ & 106 & $8 \%$ \\
\hline Boarding and alighting delay & 33 & $3 \%$ & 122 & $9 \%$ \\
\hline Delay by stopped or parked vehicle & 9 & $1 \%$ & 17 & $1 \%$ \\
\hline Delay by vehicle queue in front of traffic signals & 19 & $2 \%$ & 6 & $0 \%$ \\
\hline Delay by more than one type or other types & 95 & $8 \%$ & 23 & $2 \%$ \\
\hline
\end{tabular}

*Number of delayed buses / total valid data records.

In general, delays occurred more frequently at bus bays than at curb-side stops. The percentage of delayed buses at bus bays was more than two times that of the percentage at curb-side stops ( $43 \%$ vs. $20 \%$ ). Re-entry delay was the major delay at bus bays. The proportion of bus queuing delays at bus bays was slightly higher than at curbside stops ( $9 \%$ vs. $8 \%$ ). The reason might be that re-entry delays at bus bays increase the amount of time a bus occupies the berth. A major delay at curb-side stops was due to passengers boarding and alighting; such delay occurred less frequently at bus bays ( $9 \%$ vs. 3\%). Due to parking regulation that prohibits parking within 9 meters of a bus stop in Singapore, bus delays caused by stopped or parked vehicles at bus bays and curb-side stops are low (1\% vs. 1\%). According to the survey stop selection criteria, the percentage of delays caused by traffic signals is nearly zero. There is a large difference in terms of passenger boarding and alighting delay between bus bays and curb-side stops, as shown in Table 4.

TABLE 4. Boarding and Alighting Delay at Bus Bays and Curb-Side Stops

\begin{tabular}{|c|c|c|c|c|c|c|}
\hline \multirow[b]{2}{*}{ BSSP } & \multicolumn{3}{|c|}{ Bus Bay } & \multicolumn{3}{|c|}{ Curb-side Stop } \\
\hline & $\begin{array}{l}\text { Average } \\
\text { Number of } \\
\text { Passengers }\end{array}$ & $\begin{array}{l}\text { Average Number of } \\
\text { Passengers (with Boarding } \\
\text { and Alighting Delay) }\end{array}$ & $\begin{array}{c}\text { Number of } \\
\text { Boarding and } \\
\text { Alighting Delays }\end{array}$ & $\begin{array}{l}\text { Average } \\
\text { Number of } \\
\text { Passengers }\end{array}$ & $\begin{array}{l}\text { Average Number of } \\
\text { Passengers (with Boarding } \\
\text { and Alighting Delay) }\end{array}$ & $\begin{array}{c}\text { Number of } \\
\text { Boarding and } \\
\text { Alighting Delays }\end{array}$ \\
\hline Pair 1 & 9.34 & 13.00 & 4 & 3.87 & 5.91 & 11 \\
\hline Pair 2 & 1.08 & 2.00 & 2 & 2.99 & 4.50 & 2 \\
\hline Pair 3 & 1.64 & 1.60 & 5 & 4.45 & 6.08 & 25 \\
\hline Pair 4 & 2.93 & 4.50 & 8 & 10.76 & 9.54 & 26 \\
\hline Pair 5 & 1.80 & 1.40 & 5 & 2.16 & 3.11 & 18 \\
\hline Pair 6 & 1.87 & 5.40 & 5 & 2.84 & 3.25 & 28 \\
\hline Pair 7 & 2.36 & 3.33 & 3 & 2.16 & 3.86 & 7 \\
\hline Pair 8 & 3.22 & 2.00 & 1 & 1.75 & 3.40 & 5 \\
\hline Overall & 2.56 & 4.42 & 33 & 3.56 & 5.45 & 122 \\
\hline
\end{tabular}


As shown in Table 4, the passenger demand at the bus bay and curb-side stops within one survey pair was not always similar, which could be one of the reasons for the difference in the boarding and alighting delays. Table 4 includes the overall average number of passengers boarding and alighting from each bus, the average number of passengers boarding and alighting from each bus with boarding and alighting delay, and the number of boarding and alighting delays encountered by each stop. It is possible that a high passenger volume at stops could increase the probability of encountering boarding and alighting delays_-for example, at pairs 3, 4, 5, and 6. There are also some exceptions-for example, the bus bay in pair 1 has a larger passenger volume but a lower number of boarding and alighting delays. However, the survey data do not support any further investigation of this issue. According to daily observation, passengers waiting at curb-side stops were found to be better distributed in the waiting area or even outside. This could be another reason for the increased boarding and alighting delay at curb-side stops.

\section{Deceleration and Acceleration Times}

The data analysis of deceleration time was conducted for all recorded buses without any additional delay during the deceleration stage. The deceleration times of buses that could not enter the bus stop because it was occupied by another bus were not included. The results show an overall mean deceleration time of $8.84 \mathrm{~s}$ at bus bays and $8.53 \mathrm{~s}$ at curb-side stops. Table 5 and Figure 3 show the results of the mean deceleration times and their standard deviations for all BSSPs.

TABLE 5.

\begin{tabular}{|l|r|r|r|r|}
\hline \multirow{2}{*}{ BSSP } & \multicolumn{2}{|c|}{ Bus Bay } & \multicolumn{2}{c|}{ Curb-side Stop } \\
\cline { 2 - 5 } & Mean $[\mathrm{s}]$ & STD $^{*}[\mathrm{~s}]$ & Mean $[\mathrm{s}]$ & STD $[\mathrm{s}]$ \\
\hline Pair 1 & 10.04 & 1.70 & 10.41 & 1.60 \\
\hline Pair 2 & 8.71 & 0.96 & 8.00 & 0.67 \\
\hline Pair 3 & 7.88 & 1.08 & 8.45 & 1.31 \\
\hline Pair 4 & 8.81 & 0.90 & 8.61 & 0.90 \\
\hline Pair 5 & 8.88 & 1.10 & 7.99 & 0.99 \\
\hline Pair 6 & 8.19 & 1.14 & 8.06 & 0.93 \\
\hline Pair 7 & 9.02 & 1.17 & 8.83 & 1.29 \\
\hline Pair 8 & 9.60 & 0.90 & 9.01 & 0.92 \\
\hline Overall & 8.84 & 1.29 & 8.53 & 1.25 \\
\hline
\end{tabular}

STD: Standard deviation 
FIGURE 3.

Deceleration times at bus bays and curb-side stops

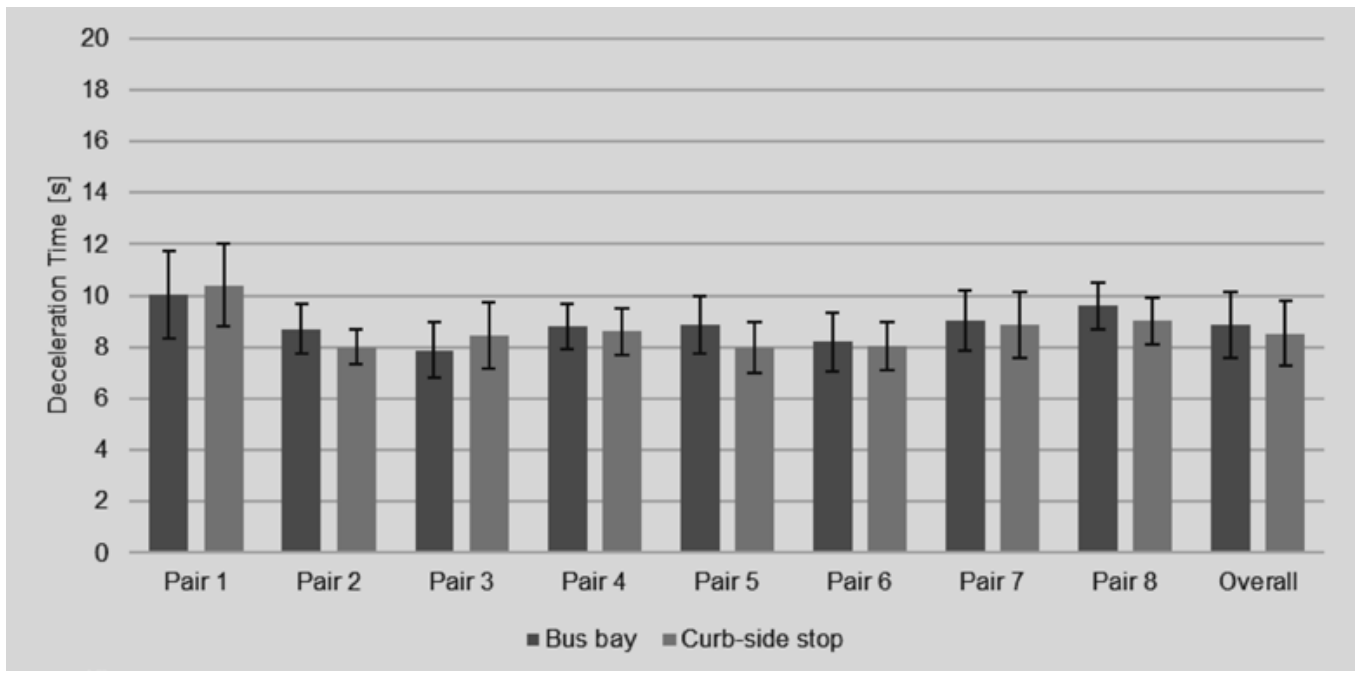

According to the results, the deceleration times vary among locations. In addition, within one survey pair, the average deceleration times and their standard deviations differ. For example, at pairs 1 and 3, a higher average deceleration time was observed at curb-side stops, whereas the other pairs show different results. A normality test was conducted, and the results show that a normal distribution is not plausible for the deceleration times. A two-tailed Wilcoxon signed rank test was applied to determine if there was any difference between bus bays and curb-side stops in terms of deceleration times and standard deviations (Rice 2007). The result $\left(T=9>3=T^{*}\right.$ ) shows that there is no significant difference for both deceleration times and standard deviation at the 0.05 significance level.

As with the deceleration times, the acceleration times were analyzed for bus bays and curb-side stops. It is very difficult to differentiate between acceleration times and re-entry delays, since the acceleration will be slow if the bus cannot re-enter the road because of running traffic. Therefore, both time components were combined. Additionally, the acceleration times without any re-entry delay at bus bays were filtered and studied separately. The results are shown in Table 6 and Figure 4.

TABLE 6. and Curb-side Stop

\begin{tabular}{|l|r|r|r|r|r|r|}
\hline \multirow{2}{*}{ BSSP } & \multicolumn{2}{|c|}{ Bus Bay } & \multicolumn{2}{c|}{ Bus Bay, without Re-entry Delay } & \multicolumn{2}{c|}{ Curb-side Stop } \\
\cline { 2 - 7 } & Mean $[\mathrm{s}]$ & \multicolumn{1}{c|}{ STD* $[\mathrm{s}]$} & \multicolumn{1}{c|}{ Mean $[\mathrm{s}]$} & \multicolumn{1}{c|}{ STD $[\mathrm{s}]$} & \multicolumn{1}{c|}{ Mean [s] } & \multicolumn{1}{c|}{ STD $^{*}[\mathrm{~s}]$} \\
\hline Pair 1 & 11.99 & 3.05 & 10.61 & 1.21 & 11.98 & 1.68 \\
\hline Pair 2 & 12.94 & 4.12 & 10.50 & 1.14 & 10.58 & 1.26 \\
\hline Pair 3 & 9.66 & 2.08 & 9.26 & 1.57 & 9.79 & 2.17 \\
\hline Pair 4 & 10.49 & 2.26 & 9.74 & 1.13 & 9.77 & 1.65 \\
\hline Pair 5 & 11.76 & 5.23 & 9.25 & 1.36 & 8.75 & 1.60 \\
\hline Pair 6 & 11.07 & 2.33 & 10.15 & 1.20 & 9.45 & 1.46 \\
\hline Pair 7 & 13.35 & 5.12 & 10.01 & 1.73 & 10.16 & 2.07 \\
\hline Pair 8 & 10.28 & 3.05 & 8.97 & 1.35 & 9.02 & 1.75 \\
\hline Overall & 11.35 & 4.32 & 8.84 & 1.29 & 9.73 & 1.91 \\
\hline
\end{tabular}

STD: Standard deviation 
Given that normality is not plausible for acceleration times, the one-tailed Wilcoxon signed rank test shows that the acceleration times at bus bays are longer than the ones at curb-side stops, with a statistical significance at the 0.05 significance level. This is caused by the large proportion of acceleration times at bus bays facing re-entry delays (17\%, Table 1) during the acceleration stage. The greater mean acceleration times (11.35s vs. $9.73 \mathrm{~s}$ at curb-side stops) and standard deviations at bus bays (4.32s vs. $1.91 \mathrm{~s}$ at curbside stops) decrease the operational efficiency and may delay the successive buses as well.

Using the two-tailed Wilcoxon signed rank test ( 0.05 significance level) to compare the acceleration times at bus bays without re-entry delay with the acceleration times at curb-side stops shows that there is no statistically-significant difference between both bus stop designs. This indicates that the re-entry delay during the acceleration is the critical time component differentiating the operational efficiency of bus bays and curbside stops.

FIGURE 4.

Acceleration times at bus bay and curb-side stop

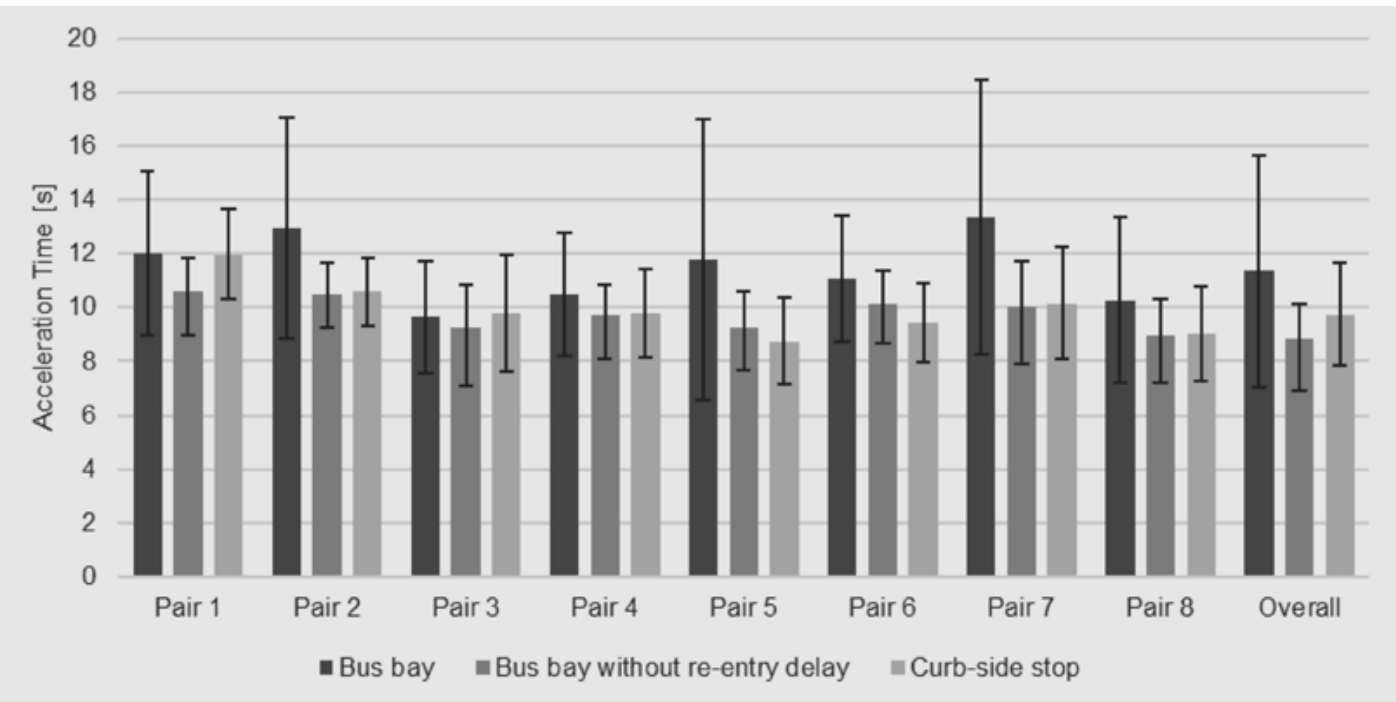

The study results show that there is no significant difference between bus bays and curb-side stops in terms of deceleration times. They fall into a stable range with an average value of $8.68 \mathrm{~s}$ and a standard deviation of $1.28 \mathrm{~s}$ among all stops regardless of the design type. On the other hand, there is a significant difference in acceleration times between bus bays and curb-side stops. The overall average acceleration time and the standard deviation at bus bays are $11.35 \mathrm{~s}$ and $4.32 \mathrm{~s}$, respectively. These times are longer than at curb-side stops, with $9.73 \mathrm{~s}$ and $1.91 \mathrm{~s}$, respectively. The difference is caused mainly by the frequently observed re-entry delays when buses are leaving the bus bays.

\section{Dwell Time}

The dwell time of each bus, together with the number of boarding and alighting passengers, was collected to analyze the differences in the average boarding/alighting time per passenger with respect to the different bus stop designs. 
Due to the operation requirements for boarding and alighting, passengers can board a bus from the front door only, but can alight from any door. Assuming that the boarding and alighting times per passenger are similar, the following equations could be used to estimate the average boarding and alighting time per passenger:

$$
\begin{aligned}
& T=t \times P+C \\
& P=\max \left\{\left(B+A_{1}\right), A_{2}\left(, A_{3}\right)\right\}
\end{aligned}
$$

where

$T$ is the total dwell time. It is dependent on the number of passengers boarding and alighting, average boarding or alighting time per passenger, and some constant time component which includes door opening and closing time.

$t$ is the boarding/alighting time per passenger.

$P$ is the maximal number of passengers boarding and alighting at one door.

$C$ is the unused dwell time, which quantifies the sum of the time gaps between bus arrival, passenger boarding and alighting, and bus' departure.

$B$ is the number of passengers boarding from the front door.

$A_{i}$ is the number of passengers alighting from the $i^{\text {th }}$ door of the bus; $i=1$ for the front door, $i=2$ for the rear door of single-deckers and double-deckers or the middle door of the articulated buses, and $i=3$ for the rear door of the articulated buses.

Because the boarding/alighting time is related to the design of the buses, the study was conducted per different bus type. The data from all valid bus survey results without passenger boarding/alighting delays were used for the calculation of the average boarding and alighting time per passenger. The results of the linear regression model with outlying residuals filtered are shown in Table 7.

TABLE 7.

\begin{tabular}{|l|l|c|c|c|c|}
\hline $\begin{array}{c}\text { Stop } \\
\text { Design }\end{array}$ & \multicolumn{1}{|c|}{ Bus Type } & $\begin{array}{c}\text { Average Boarding/ } \\
\text { Alighting Time per } \\
\text { Passenger [s] }\end{array}$ & $\begin{array}{c}\text { Unused } \\
\text { Dwell } \\
\text { Time [s] }\end{array}$ & $\mathbf{R}^{2}$ & $\begin{array}{c}\text { Sample } \\
\text { Size }\end{array}$ \\
\hline \multirow{4}{*}{ Bus Bay } & Single-decker & 1.43 & 5.68 & 0.70 & 519 \\
\cline { 2 - 7 } & Double-decker & 1.62 & 5.20 & 0.85 & 202 \\
\cline { 2 - 7 } & Articulated bus & 1.48 & 6.49 & 0.76 & 142 \\
\cline { 2 - 7 } & Overall & 1.52 & 5.60 & 0.77 & 863 \\
\hline \multirow{4}{*}{$\begin{array}{l}\text { Curb-side } \\
\text { Stops }\end{array}$} & Single-decker & 1.34 & 6.37 & 0.64 & 557 \\
\cline { 2 - 7 } & Double-decker & 1.19 & 6.99 & 0.64 & 287 \\
\cline { 2 - 7 } & Articulated bus & 1.30 & 7.64 & 0.95 & 121 \\
\cline { 2 - 7 } & Overall & 1.33 & 6.52 & 0.86 & 963 \\
\hline
\end{tabular}

As shown in Figure 5, the average boarding/alighting times per passenger at bus bays are always larger than at curb-side stops, by $14 \%$ overall $(0.2 \mathrm{~s})$. The major reason is that the bus bays require drivers to make an additional maneuver to approach the curb. This results in a gap between the bus and the curb and requires the passenger to make additional steps onto the road before boarding and after alighting from the bus. 
FIGURE 5.

Average boarding/alighting time per passenger

per bus type

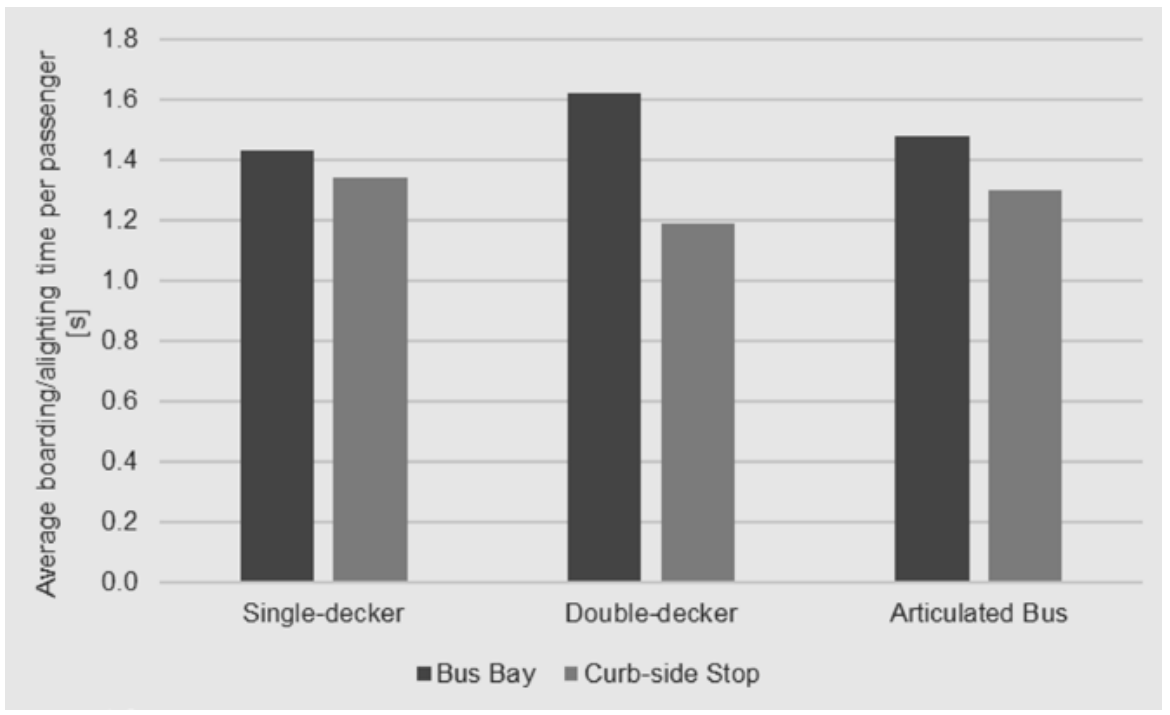

Bus bays usually have slightly shorter unused dwell times than curb-side stops-less than 1s (Figure 6). For all the data records used for this calculation, the average $P$ value (Equations 1 and 2, the maximal number of passengers boarding and alighting at one door) is 3.4 at bus bays and 4.2 at curb-side stops. As the unused dwell time quantifies the sum of the time gaps between bus arrival, passenger boarding and alighting, and bus departure, the difference could have multiple reasons, including passenger volume, passenger distribution at stops, driver behaviour during arrival and departure, etc. The result is in line with the result of the share of different delay types in Table 3, which shows that curb-side stops have a higher percentage of boarding and alighting delays. This seems to be a specific result of this survey and should not be generalized. One possible explanation could be the larger passenger volume at the curb-side stops than at the bus bays in five of the BSSPs. More passenger boarding and alighting increases the possibility of longer unused dwell times. Further investigation into the reasons is beyond the scope of this study.

FIGURE 6.

Unused dwell time per bus type

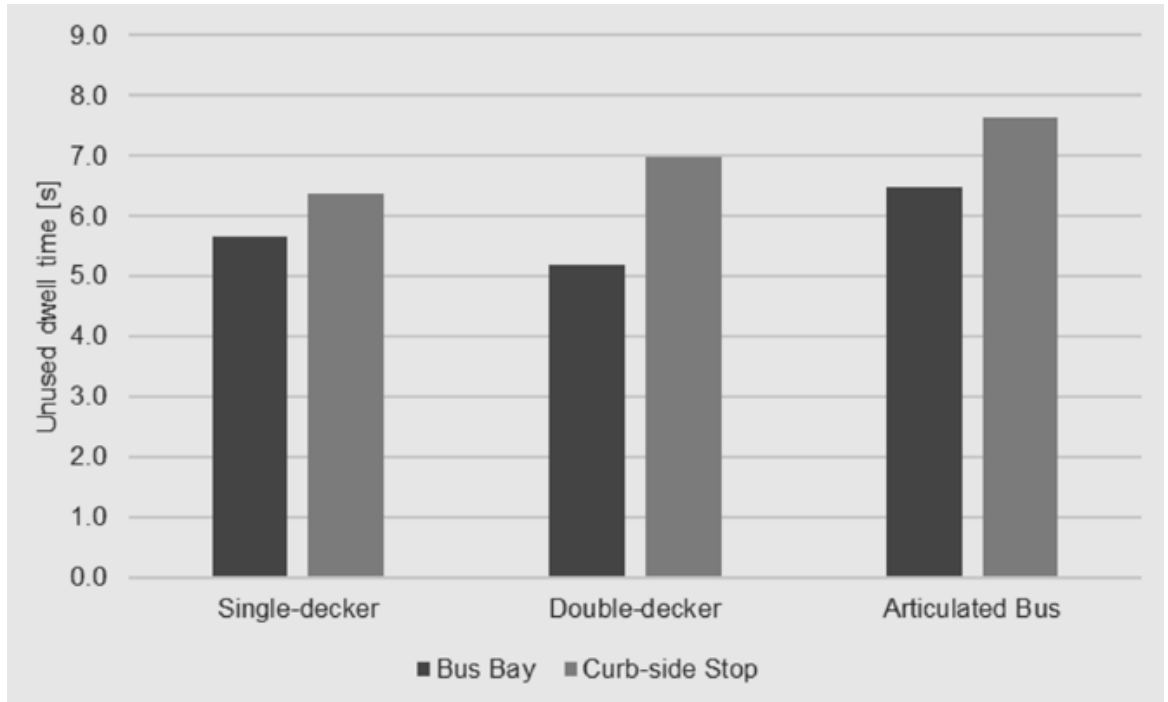


As a result of the delays, bus bays require longer boarding/alighting times per passenger for all bus types. This characteristic will increase the dwell time at bus bays compared with curb-side stops with similar passenger demand. Hence, the operational efficiency of bus bays in terms of dwell time is lower than that of curb-side stops.

\section{Conclusion and Discussion}

This paper aimed to compare the operational differences of bus bays and curb-side stops, using Singapore as a case study. A survey was conducted at eight different locations across Singapore to collect the bus operating time components, including encountered delay types, deceleration times, dwell times, passenger volumes, and acceleration times. The results show that bus bays are twice as likely to encounter delays than curb-side stops. This difference is caused mainly by re-entry delays during departure from the bus bays.

Compared to other surveys (TABLE 1), the survey conducted in Singapore provides a comprehensive data set on bus operation at stops. In terms of average acceleration time and deceleration time, international results show deceleration takes from $8.5 \mathrm{~s}$ to $11.11 \mathrm{~s}$ and acceleration takes from $10.2 \mathrm{~s}$ to $11.12 \mathrm{~s}$. In Singapore, deceleration takes, on average, $8.84 \mathrm{~s}$ at bus bays and $8.53 \mathrm{~s}$ at curb-side stops, and average acceleration takes $11.35 \mathrm{~s}$ at bus bays and $9.73 \mathrm{~s}$ at curb-side stops. Both deceleration and acceleration times are slightly lower than the corresponding international survey results. The analysis shows that there is no statistically-significant difference between the deceleration times of the two designs. However, the survey also shows a great increment in acceleration times at bus bays; this result is in line with those of the other surveys. It can be concluded that commonly-observed re-entry delay is the major defect of bus bays.

As for the dwell time and average boarding and alighting time per passenger (shown in Table 7), the survey shows that curb-side stops require shorter boarding and alighting times (1.33s) than bus bays (1.52s). But the average boarding and alighting time per passenger in Singapore is shorter than those of all the other surveyed cities (ranging from $1.7 \mathrm{~s}$ to $4.0 \mathrm{~s}$, Table 1). This is mainly because all buses are equipped with doublechannel doors in Singapore. Additionally, this study reveals that in Singapore, boarding and alighting at bus bays is shorter than at curb-side stops. The numeric results, in comparison with international results, show that all operating time components of buses at stops vary from location to location. Thus, when planning public transport operation, it is recommended that agencies and operators conduct local surveys to carry out best-fitting local operational plans.

Curb-side stops, compared with bus bays, have similar deceleration times, shorter and more reliable acceleration times due to the absence of re-entry delays, and require less time for passengers to get on or off the bus. In terms of operational efficiency, curbside stops, therefore, have better performance. However, they also have slightly longer unused dwell times than bus bays. The exact reasons for this will be studied via specific surveys in the future. 
In practice, both types are commonly used. Curb-side stops have better efficiency but affect private traffic by blocking an entire lane. On the other hand, bus bays have less impact on private cars and guarantee better safety (Fitzpatrick et al. 1996); as trade-offs, they require longer operating times and reduce efficiency. As a result, choice of bus stop design should consider different aspects, including traffic volume, passenger demand, operational requirements (trunk service or feeder service), etc. For public transport prioritization, curb-side stops are suggested. Bus bays are suggested to be applied along major arterials with high-speed movements for safety reasons.

\section{Acknowledgment}

The content of the paper and any opinions expressed are the sole responsibility of the authors. This work was financially supported by the Singapore National Research Foundation under its Campus for Research Excellence and Technological Enterprise (CREATE) program. The data collection in this study was conducted by second author Yao Yang for her master's thesis.

\section{References}

Chen, S., R. Zhou, Y. Zhou, and B. Mao. 2013. "Computation on Bus Delay at Stops in Beijing through Statistical Analysis." Mathematical Problems in Engineering, 2013: $1-9$.

Dueker, K. J., T. J. Kimpel, and J. G. Strathman. 2004. "Determinants of Bus Dwell Time." Journal of Public Transportation, 7(1): 21-40.

Fitzpatrick, K., et al. 1996. Report 19: Guidelines for the Location and Design of Bus Stops. Washington, DC: National Academy Press.

Genivar. 2011. "Operational Impacts and Policy Implication of Bus Bay in the City of Ottawa." Ottawa, GENIVAR, Inc.

Koshy, Z. R., and V. T. Arasan. 2008. "Influence of Bus Stops on Flow Characteristics of Mixed Traffic." Journal of Transportation Engineering, 8(131).

Land Transport Authority. 2015. "Singapore Land Transport Statistics in Brief 2015." https://www.Ita.gov.sg/content/dam/ltaweb/corp/PublicationsResearch/files/ FactsandFigures/Statistics\%20in\%20Brief\%202015\%20FINAL.pdf, accessed September 2014.

Rajbhandari, R., S. Chien, and J. Daniel. 2003. "Estimation of Bus Dwell Times with Automatic Passenger Counter Information." Transportation Research Record, 1841: 120-127.

Rakha, H., and Y. Zhang. 2004. "Sensitivity Analysis of Transit Signal Priority Impacts on Operation of a Signalized Intersection." Journal of Transportation Engineering, 130(6): 796-804.

Rice, J. A. 2007. Mathematical Statistics and Data Analysis, 3rd Edition. Duxbury Press. 
Shrestha, R., and E. Zolnik. 2013. "Eliminating Bus Stops: Evaluating Changes in Operations, Emissions and Coverage." Journal of Public Transportation, 16(2):153175.

Sun, L. et al. 2014. "Models of Bus Boarding and Alighting Dynamics." Transportation Research Part A: Policy and Practice, 69: 447-460.

Surprenant-Legault, J. and A. El-Geneidy. 2011. "Introduction of Reserved Bus Lanes: Impact on Bus Running Time and On-time Performance." Transportation Research Record, 2218: 10-18.

Tirachini, A. 2013. "Bus Dwell Time: The Effect of Different Fare Collection Systems, Bus Floor Levels, and Age of Passengers." Transportmetrica A: Transport Science, 9(1): 28-49.

Transport for London. 2006. “Accessible Bus Stop Design Guidance." London: Transport for London.

Wang, C., et al. 2016. "Modeling Bus Dwell Time for Bus Stops." Washington, DC.

Xu, Z., A. V. Kwami, and X. Yang. 2010. "Bus Delay Factor Analysis At and Near the Bus Stop and An Approach to Delay Estimation." Journal of Wuhan University of Technology, 34(5): 877-881.

Yu, B., W. H. Lam, and M. L. Tam. 2011. "Bus Arrival Time Prediction at Bus Stop with Multiple Routes." Transportation Research Part C: Emerging Technologies, 19(6): 1157-1170.

Zhou, H., S. Bromfield, and A. Datz. 2009. "Moving the Bus Back into Traffic SafelySignage and Lighting Configuration." ITE Journal, March: 40-46

\section{About the Authors}

XIAODONG LIU (xiaodong.liu@tum-create.edu.sg) is with TUM CREATE Ltd. in Singapore.

YAO YANG (yao.yang@tum-create.edu.sg) is with TUM CREATE Ltd. in Singapore. Meng MeNG (meng.meng@tum-create.edu.sg) is with TUM CREATE Ltd. in Singapore. ANDREAS RAU (andreas.rau@tum-create.edu.sg) is with TUM CREATE Ltd. in Singapore. 